\title{
The Effect of Pain Training Before Thoracotomy Operation on Postoperative Pain Levels
}

Etik Kurul Onayı: Akdeniz Üniversitesi Tıp Fakültesi Klinik Araştırmalar Etik Kurulu'ndan onaya alınmıștır (28.11.2018 / 70904504-532).

Çıkar Çatışması: Çıkar çatışması yoktur.

Finansal Destek: Bu çalış̧ma, herhangi bir fon tarafından desteklenmemiştir.

Hasta Onamı: Her hastadan yazııı olarak bilgilendirilmiş onam alındı.
Ethics Committee Approval: It was approved by the Akdeniz University Faculty of Medicine Clinical Research Ethics Committee (28.11.2018 / 70904504-532).

Conflict of Interest: There is no conflict of interest.

Funding: This study was not supported by any funding.

Informed Consent: Written informed consent was obtained from each patient

Cite as: Gündüz E, Keskin H. Torakotomi ameliyatı öncesi ağrı eğitiminin postoperatif ağrı düzeylerine etkisi. GKDA Derg. 2020;26(4):213-20.

öz

Amaç: Postoperatifağrı tüm dünyada hastaların sıklıkla yakındığı bir durumdur. Çalışmamızda, elektif torakotomi ameliyatı öncesi hastaların ağrı eğitiminin torakotomi sonrası dönemde ağrı düzeylerine etkisini araştırmayı amaçladık.

Yöntem: Çalışmaya herhangi bir nedenle torakotomi uygulanacak 100 hasta dahil edildi. Çalışma grubuna torakotomiden 24-48 saat öncesinde; postoperatif oluşabilecek ağrı ve ağrının kontrolünün nasıl sağlandığı, hastanın ağrıyı azaltmak amaçlı neler yapabileceğini içeren 20 ile $30 \mathrm{dk}$. süren bir eğitim verildi. Hastalar ağrı konusunda eğitim verilen ve verilmeyen olarak 2 gruba ayrıldı. Ekstübasyon saati 0 olarak kabul edildi. 4., 8., 12., 16., 20. ve 24. saatlerde hastalara vizuel ağrı skalası (VAS) üstünden ağrıları soruldu. Aynı saatlerde solunum sayısı, tansiyon, kalp hızı ve oksijen saturasyon düzeyleri kayıt altına alındı.

Bulgular: iki grup arasında vizuel ağrı skorlamasının karşılaştırılmasında 4. saatte ölçülen değerler anlamsız, daha sonraki değerler istatistiksel olarak anlamlı çıkmıştır.

Sonuç: Bu çalışmanın sonuçlarına göre, torakotomi ameliyatı öncesi ağrı eğitiminin hastalarda postoperatif vizüel ağrı skorlarını giderek azalttığını göstermiştir.

Anahtar kelimeler: torakotomi, ağrı eğitimi, postoperatif ağrı

\section{ABSTRACT}

Objective: Postoperative pain is a condition that patients frequently complain about all over the world. The aim of this study was to investigate the effect of pain training before elective thoracotomy on postoperative pain levels in patients.

Method: A total of 100 patients who underwent thoracotomy for any indication were included in the study. Patients were given a 20-30 minute training on postoperative pain and how the pain is controlled, and what the patient can do to minimize the pain 24-48 hours before thoracotomy. The patients were divided into two groups; those that were trained and those that were not trained on postoperative pain. Extubation time was accepted as baseline (0 hour). At the 4., 8., 12., 16., 20. and 24. hours, patients were asked to pinpoint their pain perception on the visual pain scale (VAS). Respiratory rate, blood pressure, heart rate, and oxygen saturation levels were recorded at same hours.

Results: When VAS scores were compared between the two groups, no significant difference was found in the values measured at the $4^{\text {th }}$ hour whereas there was a significant difference between the subsequent values.

Conclusion: The results of this study showed that pain training before thoracotomy operation gradually decreased postoperative VAS pain scores in patients.
Received/Geliş: 07.09.2020

Accepted/Kabul: 18.11.2020

Published Online/Online yayın: 31.12 .2020

Emel Gündüz

Akdeniz Üniversitesi Tıp Fakültesi Anesteziyoloji ve Reanimasyon

Anabilim Dalı

Antalya, Türkiye dregunduz@hotmail.com ORCID: 0000-0002-0306-9770

H. Keskin 0000-0002-5736-5954 Akdeniz Üniversitesi Tıp Fakültesi Gögüs Cerrahisi Anabilim Dalı Antalya, Türkiye

Keywords: thoracotomy, pain training, postoperative pain 


\section{Giriş}

Uluslararası Ağrı Araştırmaları Derneği (IASP) tarafından ağrı ; var olan ya da olası doku hasarına eşlik eden ya da bu hasar ile tanımlanabilen, hoş olmayan emosyonel bir durum olarak tanımlanır [1,2]. Torakotomi ağrısı, en şiddetli postoperatif ağrılardan olup, postoperatif komplikasyonların oluşumunda önemli bir rol oynar. İyi ağrı kontrolü sağlanamayan hastalarda öksürmenin, derin ve düzenli solumanın engellenmesi sonucu, doku hipoksisi gelişmektedir ${ }^{[3-5]}$. Toraks cerrahisi sonrası, ortaya çıkan ağrııın etkin bir analjezik yönetimle giderilmesi, iyileşmeyi hızlandırarak, komplikasyon oranını azaltmaktadır.

Postoperatif ağrı; akut olarak cerrahi travma ile başlayan ve doku iyileşmesi boyunca giderek azalan, genellikle doku hasarı ya da ağrılı hastalıktan sonra belirli bir zamanda başlayıp birkaç hafta süren duruma akut ağrı denir. Daima nosiseptif nitelikte olup, vücuda zarar veren bir olayın varlığını gösteren değerli bir bulgudur ${ }^{[5]}$. Her yıl birçok kişiye, cerrahi işlem uygulanmakta ve cerrahiye bağı farklı derecelerde postoperatif dönemde ağrı oluşmaktadır ${ }^{[6]}$.

Postoperatif ağrı, öngörülebilir ve tedavi edilebilir olmasına; yeni ilaçların ve uygulama yöntemlerinin gelişmesine rağmen, halen günümüzde önemli bir sorundur ${ }^{[7]}$. Etkin postoperatif ağrı kontrolü; kişiye özgü bütüncül bir yaklaşım ve multidisipliner ekip anlayışıyla gerçekleştirilebilir. Postoperatif ağrının tanımlanması ve kontrol altına alınmasında, ağrı yönetim metodlarının uygulanmasında hastanın bilgilendirilmesi oldukça etkin rol oynar ${ }^{[6]}$.

Ağrıyı algılama ve karşı tarafa verilen tepkiler kişiden kişiye değişir. Bu nedenle hastadan detaylı anamnez almak, hastayı sürekli gözlemlemek ve uygun ölçüm yöntemlerinden faydalanarak değerlendirmek önemlidir ${ }^{\left[{ }^{[6]}\right.}$.

Bu çalışmada, torakotomi yapılan hastalara preoperatif erken dönemde verilecek olan ağrı eğitiminin torakotomi sonrası dönemde ağrı düzeylerine etkisini araştırmayı amaçladık.

\section{GEREÇ ve YÖNTEM}

Bu prospektif çalışma Akdeniz Üniversitesi Göğüs Cerrrahisi Anabilim dalında herhangi bir nedenle torakotomi yapılan 100 hastayı içermektedir. Hastalar ağrı konusunda eğitim verilen ve verilmeyen olarak iki gruba ayrıldı. Postoperatif ağrı düzeyinin ölçülmesi için kullanılacak olan, yetişkinler için vizuel ağrı skalasını değerlendiremeyecek olan, çalışmaya katılmak istemediğini beyan edenler ve ilk 24 saat içinde herhangi bir nedenle reoperasyona alınan hastalar çalışma dışı bırakıldı.

Çalışma protokolü Akdeniz Üniversitesi Tıp Fakültesi Klinik Araştırmalar Etik Kurulu (onay numarası 70904504-532) tarafından onaylandı. Her hastadan yazılı olarak bilgilendirilmiş onam alındı. Çalışma Helsinki Deklarasyonu ilkelerine uygun olarak gerçekleştirildi.

Çalışma grubuna, torakotomi öncesinde cerrahi sonrasında oluşabilecek ağrı ve ağrının kontrolünün nasıl sağlandığını, hastanın ağrıyı azaltmak amaçlı neler yapabileceğini içeren 20-30 dakikalık bir eğitim verildikten sonra postoperatif ağrı düzeylerini karşılaştırmayı amaçlamıştır. Hastalara geçirecekleri cerrahi operasyondan 24-48 saat önce torakotomi sırasında kimlerin bulunacağı, nasıl bir kesi ile yapılacağı, operasyonun yaklaşık kaç saat süreceği, operasyon sonrası yoğun bakım ünitesinde yakın takip edileceği söylendi. Kendisine rutinde ağrı kesici tedavi yapılacağı, insizyon yerinin desteklenmesi yöntemi ve ağrısının devamında, yoğun bakım çalışanlarına iletmesi durumunda ek analjezik yapılacağı, her zaman yanında görevli doktor ve hemşirelerin bulunacağı konusunda bilgilendirildi.

Postoperatif bütün hastalar göğüs cerrahisi yoğun bakım ünitesine çıkartılan ,hastalara ağrı skorlamasından bağımsız olarak tramadol hidroklorür $100 \mathrm{mg}$ $3 \times 1$ intravaskuler ve Diklofenak sodyum 100 mg 1x1 intramuskuler olarak verildi. Vizuel ağrı skorları sekizin üstünde olan ve ağrısı solunum ekzersizlerini yapmasına engel olan hastalara ek analjezi (Diklofenak 
sodyum veya Morfin $\mathrm{HCL}$ ) uygulanarak kayıt altına alındı.

Weaning kriterlerini (yeterli nörolojik yanıt, yeterli kas kuvveti, yüksek doz inotropik / vazoaktif destek olmadan hemodinamik stabilite, \% 40 oksijen fraksiyonu olan ve arteriyel $\mathrm{PO}_{2}>70 \mathrm{mmHg}$ ) sağlayan hastalar ekstübe edildi. Ekstübasyon saati 0 olarak kabul edildi. 4, 8, 12, 16, 20 ve 24. saatlarde hastalara vizuel ağrı skalası üstünden ağrıları soruldu. Eşzamanlı olarak solunum sayısı, tansiyon, kalp hızı ve oksijen saturasyon düzeyleri kayıt altına alındı.

\section{İstatiksel Analiz}

Toplanan veriler IBM SPSS 23 programında veri tabanına girildi ve tüm istatistiksel analizler aynı programda gerçekleştirildi. Sürekli değişkenler aritmetik ortalama, standart sapma, minimum ve maksimum değerleri olarak, kategorik değişkenler ise frekans ve yüzde olarak ifade edildi. Gruplar arası karşılaştırmalarda; kategorik değişkenler için Ki-kare testi, parametrik değişkenler için Student's t-testi ve nonparametric değişkenler için Mann-Whitney $U$ testi kullanıldı. Parametreler arasındaki ilişki Pearson'un koreIasyon analizi ile belirlendi. İstatistiksel anlamlılığı belirtmek için $p<0,05$ değeri kabul edildi.

\section{BULGULAR}

Olgular eşit sayıda (50), eğitim verilen ve verilmeyen olmak üzere iki gruba ayrılarak çalışmaya alındı. Eğitim verilen grubun yaş ortalaması 50,52 $\pm 9,93$ kadın/erkek oranı 22/28'dir. Eğitim verilmeyen grubun yaş ortalaması $52,58 \pm 10,81$ kadın/erkek oranı ise 19/31'dir. İki grup arasında yaş ve cinsiyet açısından istatistiksel olarak farklılık yoktu.

İki grup arasında Vizüel Ağrı Skorlamaları karşılaştırıldığında 8, 12, 16, 20 ve 24. saatlerde farklılıklar anlamlı ( $p$ değerleri sırasıyla $p=.030, p=.042, p=.045$, $p=.011, p=.012$ ) olarak saptandı. Her iki grupta da vizüel ağrı skorlamaları giderek azalma tespit edildi. Ancak bu azalış eğitim verilen grupta 20-24.saatlerde anlamsız saptandı. Eğitim verilmeyen grupta ise
12-16-20-24. saatler arasında istatiksel olarak anlamlı değildi (Şekil 1).

İki grup arasında Vizuel ağrı skorlamasının karşılaştırılmasında 4. saatte ölçülen değerler dışında ( $p=.060)$ diğer değerlerin istatistiksel olarak anlamlı çıkmıştır. 4. saatte ki değerin anlamlı çıkmaması hastaların yeterli uyanıklıkların olmaması ve eğitimde verilen ağrı azaltma yöntemlerini yeterli uygulayamaması olabilir.

Ekstra analjezik yapılan hastalara bakıldığında eğitim verilen grupta ise 2 hastaya diklofenak sodyum 2 hastaya ise Morfin HCL yapıldı. Kontrol grubunda 8 hastaya diklofenak sodyum 4 hastaya ise Morfin $\mathrm{HCL}$ uygulandı. İki grup arasında yapılan Ki-kare analizlerinde Diklofenak sodyumun $P$ değeri 0.045 olarak saptandı. Fakat yates düzeltmesi yapıldığında P değeri 0.095 olarak saptandı. Morfin HCL yapılan hastalarda ise $p$ değeri 0.399 olarak bulundu (Tablo 1 ).

Tablo 1. Ekstra analjezik gereksinimi olan hasta sayısı.

\begin{tabular}{lcccc} 
& $\begin{array}{c}\text { Eğitim } \\
\text { verilen }\end{array}$ & $\begin{array}{c}\text { Eğitim } \\
\text { Verilmeyen }\end{array}$ & p & Yates p \\
\hline Diklofenak Sodyum & 2 & 8 & .045 & .095 \\
Morfin HCL & 2 & 4 & .399 & .673 \\
\hline
\end{tabular}

Morfin HCL benzeri ilaçların yüksek bağımlılık yapma riski nedeniyle yapılırken daha tutucu davranılması nedeniyle bu değerler bulunmuş olabilir. Daha yüksek örneklem grubu ile daha doğru sonuçlara ulaşılacağı aşikârdır.

İki grup arasında ağrı dışındaki parametrelere bakıldığında 8. ve 20. saat kalp hızında anlamlı farklılık saptandı ( $p=0.046, p=0.048$ ). Ayrıca eş zanamlı alınan oksijen saturasyonu verilerinde; 16 . saatteki saturasyon yüzdesinde saptanan anlamlılık oldukça fazlaydı $(p=0.013)$.

Bunun dışında kalan zamanlarda kalp hızı ve oksijen saturasyonu değerlerinde anlamlı farklılık yoktu. Solunum sayısı ve kan basıncı verileri değerlendirildi- 


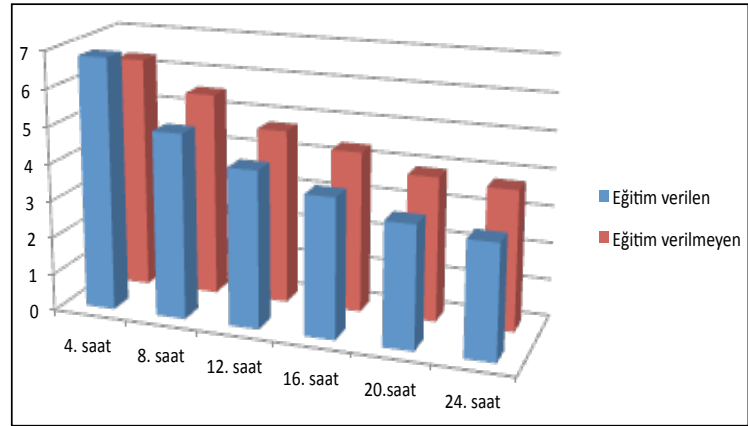

Şekil 1. Eğitim verilen ile eğitim verilmeyen grupların vizuel ağrı skorları (VAS).

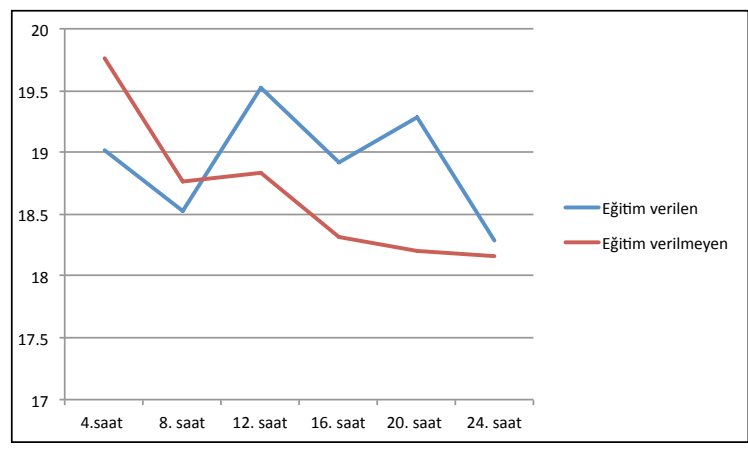

Şekil 3. Eğitim verilen ile eğitim verilmeyen hastaların solunum sayıları.

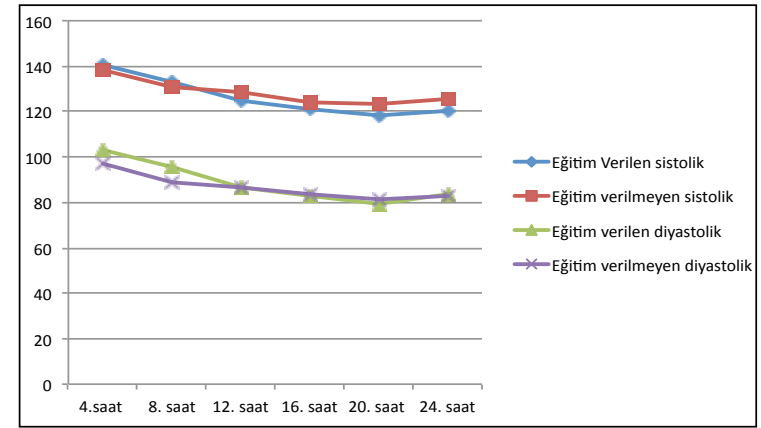

ŞEKiL 2. Eğitim verilen ile eğitim verilmeyen hastaların sistolik ve diyastolik kan basınçları.

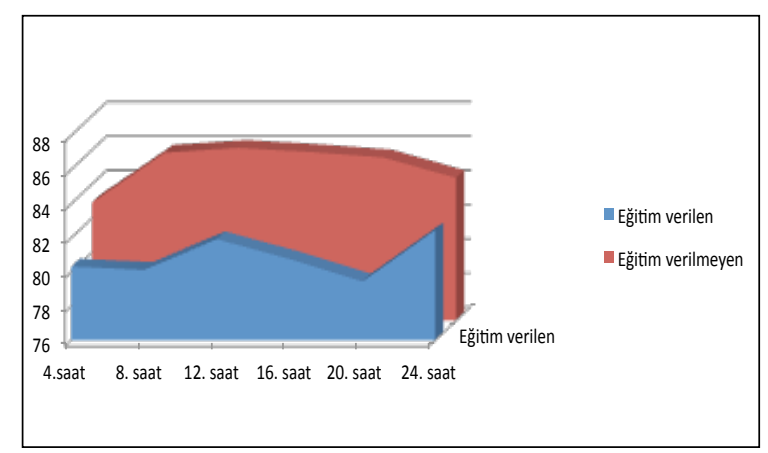

Şekil 4. EKalp hızının eğitim verilen ile eğitim verilmeyen hastalar arasında karşılaştırıması.

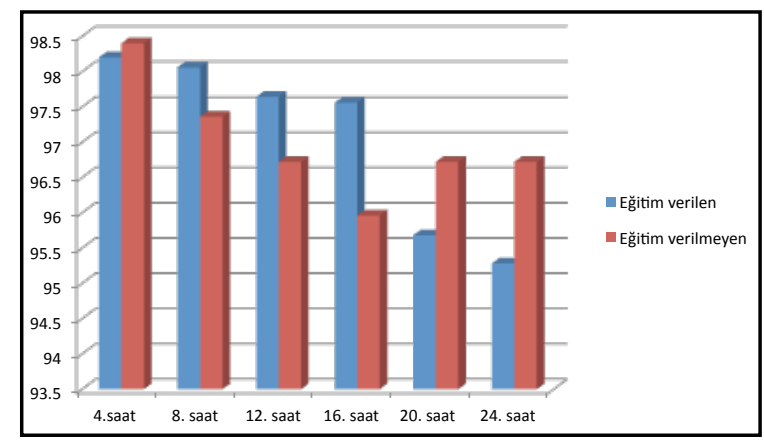

Şekil 5. Oksijen saturasyonun eğitim verilen ile eğitim verilmeyen hastalar arasında karşılaştırılması.

ğinde herhangi bir zamanda anlamlı bir farklılık saptanamadı (Şekil 2,3,4,5).

Eğitim verilen grupta vizüel ağrı skoruna paralel olarak diğer parametrelerinde değişmesini beklerdik ancak sadece 8 ve 20. Saat nabız ile 16. Saatteki oksijen saturasyonlarında istatistiksel olarak anlamlı sonuçlar elde edildi. Bunun nedeni; bu parametrele- rinin sadece ağrıya bağlı olarak değişmediğindendir. Bu tezimizi ağrı ile diğer parametreleri kıyasladığımızda, 24. saatte oksijen saturasyonu ve kan basıncı verileri dışında istatistiksel olarak anlamlı bir ilişki çıkmaması desteklemektedir. Daha geniş serilerle ve verilen medikal tedavilerin standardize edilmesi ile bu parametrelerin değerlendirilmesi daha net olarak yapılabilir. 
4, 8, 12, 16 ve 20. saatlerde ağrı ile karşılaştırılan bütün parameterelerde anlamlı ilişki tespit edilmedi. Ağrı ile diğer parametreler karşılaştırıldığında sadece 24. Saatte ölçülen tansiyon ve oksijen saturasyonu istatiksel olarak anlamlı bir ilişki tespit edildi. ( $p=0.049$, $p=0.020$ ) 24 . Saatte solunum ve kalp hızında da ağrı ile ilgili istatiksel anlamlı veriye ulaşılamadı.

\section{TARTIŞMA}

$\mathrm{Bu}$ çalışma; torakotomi operasyonu öncesi verilen ağrı eğitiminin hastalarda postoperatif ağrı düzeylerinin giderek azalmasına katkıda bulunduğunu gösterdi.

Toraks cerrahisinde; cerrahi işlem yapılacak alana ulaşmak için sıklıkla tercih edilen teknik posterolateral torakotomidir[8]. Bu teknik toraks cerrahisinde en yaygın kullanılan yöntem olmasına rağmen birçok dezavantajlarıda bulunmaktadır. Örneğin büyük kas gruplarının kesilmesine bağlı çoğunlukla mobilizasyonun sınırlanması, omuz ve üst ekstremite hareketlerinin kısıtlanması gibi istenmeyen sonuçlara yol açmaktadır ${ }^{[9]}$. En önemliside hastaların sıklıkla yakındıkları ameliyat sonrası şiddetli ağrıya neden olmaktadır. Torakotomi sonrası hastaların \%21-67 arasında değişen oranlarda şiddetli ağrı şikayetleri olmaktadır ${ }^{[8]}$. Torakotomi ağrısı sempatik sinirlerin afferent dalları tarafından inerve edilen organlardan, viseral plevradan, perikardın yaralanmasından oluşur ve frenik, vagal sinirler ile taşınır ${ }^{[10]}$. Çalışmamızda ki tüm hastalarımıza posterolateral torakotomi uygulandı.

Torakotomi sonrası gelişen ağıı kaynağının multimodal olması nedeniyle tek bir analjezi tekniği ile ağrı kontrolü çok mümkün değildir. Son yıllarda, hem akut hem de kronik ağrı kontrolünde multimodal analjezi, tek bir analjezi yaklaşımına göre torakotomi sonrası ağrı kontrolünde de tercih edilmektedir ${ }^{[8]}$. Torakotomi sonrası ağrı kontrolünde farmakolojik olan ve nonfarmakolojik olmayan yöntemler kullanılmaktadır. Farmakolojik yöntemler arasında NSAii, parenteral opioid; rejyonel yöntemler paravertebral blok, interkostal sinir bloğu, plevra içine lokal aneste- zik uygulamaları, torakal epidural yolla lokal anestezik uygulamaları sıklıkla tercih edilmektedir ${ }^{[11]}$.

Cerrahi geçiren hastalarda akut ağrının şiddetinin değerlendirilmesi etkin ağrı yönetimi için gereklidir. VAS en popüler ve en sık kullanılan skaladır. Cerrahi sonrası akut ağrı ölçümünde kullanımının ve hasta adaptasyonu kolay olduğu için daha sık tercih edilir. VAS; 0 ile 10 arası bir skaladan oluşur. 0 ağrının olmaması, 1-3 hafif ağrı, 4-6 orta şiddette ağrı ve 7-10 şiddetli ağrıyı gösterir. Orta ve şiddetli ağrıda hemen müdahale gerekmektedir. Çalışmamızda tüm hastalarımızda rutin tedavimize ek olarak; torakotomi sonrası VAS değerlerini karşılaştırdığımızda 8, 12, 16, 20 ve 24 . saatlerde farklılıklar anlamlı olarak saptandı. Ağrı eğitimi verilen grupta VAS değerlerinin düştüğünü gözlemledik.

ERAS (Enhanced Recovery After Surgery) postoperatif sonuçları iyileştirmek için multimodal, perioperatif müdahaleleri tanımlamak amacıyla kullanılan terimdir. On yıldan uzun bir zaman önce gündeme gelen ve son birkaç yıldır da toraks cerrahisinde kullanılan ERAS ; iyileşme döneminin hızlandırılması için ameliyat sürecinin farklı basamaklarında hasta bakımı hakkında öneriler içeren kanıta dayalı bir bulgular birleşimidir. ERAS uygulamalarının ilk basamağını hastayı bilgilendirme ve danışmalık yer almaktadır. ERAS, cerrahi stresi azaltarak, postoperatif ağrının azalması, fizyolojik fonksiyonların korunması ve erken mobilizasyona olanak sağlayan prosedürleri içerir. Buna bağı olarak morbitide, hastanede kalış süresinde azalmaya ve maliyette azalmaya olanak sağlar. ERAS, bir hastanın ameliyat öncesinden başlayan ve evinde sonuçlanan yolculuğunun tamamı ile ilgili değişiklikler önerir. ERAS yöntemlerinin hastaya uygulanması için hastanın bu protokolleri kabul etmesi gerekmektedir. Cerrahi ve anestezi uygulamaları ile ilgili beklentileri hedefleyen preoperatif danışmanlık korku ve kaygıyı azaltabilir buna bağlı olarak postoperatif iyileşme ve taburcu olma süreci kısalabilir. Bu nedenle cerrahi süreç cerrah, anestezist, hemşire, fizyoterapist ve diyetisyen gibi birçok meslek grubunun birlikte uyum içinde hareket edeceği 
multidisipliner bir yaklaşım gerektirmektedir ${ }^{[11,12]}$.

Refai ve ark. ${ }^{[13]}$; toraks cerrahisinde ERAS protokolünde preoperatif bilgilendirme döneminde cerrah, anestezist, hemşire ve solunum fizyoterapistinin önemi vurgulamışlardır.

Kol ve ark. ${ }^{[14]}{ }^{1}$ nın araştırmasında torakotomi operasyonu öncesi verilen ağrı kontrolü eğitiminin, hastalarda ameliyat sonrası ilk 48 saatteki hem ağrı düzeyini hem de analjeziklerin tüketimini azalttığı saptanmıştır. Hastaya ameliyattan önce, operasyon sonrası orta ya da şiddetli düzeyde ağrı yaşanabileceğinin anlatılması önemlidir. Ağrıya neden olan faktörlerin (göğüs tüpleri, insizyon yeri ve boyutu vb), ağrıyı arttıran durumlar (operasyon sonrası hareket ve öksürme vb), ağrı değerlendirmesinde kullanılacak ölçek, ağrıyı azaltan farmakolojik (opioid ve nonopioid analjezikler) ve farmakolojik olmayan (insizyon yerinin desteklenmesi, pozisyon vb) yöntemler konularında eğitim verilmelidir. Bu eğitim, hastanın ağrı yönetimi ekibinin bir parçası olduğunu görmesi ve kendi ağrı kontrolünde aktif rol oynadığını bilmesi açısından önemlidir ${ }^{[9,15]}$. Çalışmamızda hastalarımıza operasyondan 24-48 saat önce torakotomi sonrası hangi düzeyde ağrı yaşayabileceği, ağrıyı azaltmak için tedavi olarak vereceğimiz ilaçları, kendisinin ise insizyon yeri basısı ile ağrıyı azaltabileceği yöntemi 20-30 dakikalık eğitimler şeklinde anlattık. Ekstra analjezik yapılan hastalara bakıldığında eğitim verilen grupta 2 hastaya diklofenak sodyum, 2 hastaya ise Morfin $\mathrm{HCL}$ yapıldı. Kontrol grubunda ise 8 hastaya diklofenak sodyum, 4 hastaya ise Morfin $\mathrm{HCL}$ yapıldı.

Diklofenak Sodyum; fenilasetik asit türevi ve kısa yarı ömürlü bir nonsteroid antiinflamatuvar ilaçlatır (NSAii). Antiinflamatuar, antipiretik ve analjezik etkilerini selektif siklojenaz-2 enzim inhibisyonu ile prostoglandin sentezini baskılayarak gösterir. Diklofenak sodyum gastrointestinal sistemde; gastrik ülserasyon, epigastrik ağıı, kabızlık, özofajit ve ishal yapabilir. Bu yan etkiler yaşlılarda, sigara ve alkol kullananlarda daha sık ve şiddetli görülebilir. Hastalarımıza operasyon öncesi ağrı eğitimi vererek ek analjezik ihtiyacında azalma gözlemledik ${ }^{[16]}$.

Morfin torakotomi sonrası akut ağrıda sık kullanılmakta, sedasyon etkisi bulunmakta ve ağrı tedavisinde kullanılan morfin miktarı da farklılıklar göstermektedir ${ }^{[5]}$. Hastanın özellikle solunum depresyonu açısından monitörizasyonunu zorunlu kılmaktadır. Morfinin postoperatif uygulaması sırasında \% 42 oranında bulantı-kusma gibi gastrointestinal yan etkiler en fazla görülmüştür. Ayrıca solunum depresyonu, kaşıntı, uyuşukluk, idrar retansiyonu, kabızlık, konfüzyon ve kanama gibi diğer yan etkileride bildirilmiştir. Çalışmamızda; ağrı eğitimi verilen ve verilmeyen her iki gruptaki olularımızın hiçbirisinde çalışmanın durdurulmasını gerektirecek ölçüde herhangi bir komplikasyon gözlemlemedik. Bu da uyguladığımız protokollerin güvenilirliğini göstermektedir [17]. Torakotomi ağrısında operasyon öncesi ağrı eğitimiyle verilen ek morfin dozu azaltılarak hastalar yan etkilerden korunmuştur.

Torakatomi sonrası ağrı, hastanın solunum, hareket, beslenme gibi fonksiyonlarını etkileyebileceğinden, analjeziklerin neden olduğu komplikasyonlar nedeniyle bu ilaçların en az düzeyde verilmesi, ameliyat sonrası morbiditenin önlenmesi açısından önemlidir. Bu bağlamda, ameliyat sonrası analjezide farmakolojik yöntemlere farmakolojik olmayan yöntemlerin eklenmesi hem daha iyi ağrı kontrolü sağlamakta, hem de ilaçların yan etkilerini ve birbirleri ile etkileşimlerini önlenmektedir ${ }^{[11,17]}$.

Aygül ve Ulupınar'ın çalışmasında hastaların tamamına yakını (\%96.6), hasta yakınlarının bilgilendirilmesinin çok gerekli olduğunu ve bu bilgilendirmenin iyileşme sürecini hızlandırdığını bildirmişlerdir ${ }^{[18]}$.

Gräwe JS ve arkadaşlarının yaptığı 96 hastayı içeren çalışmasında; ameliyat öncesi dönemde iyi hazırlanıp, yeterli eğitim alan hastaların daha az analjezik, antiemetik, sedatif, hipnotiğe gereksinim duyduklarını, ameliyat sonrası dönemde hastanede kalış süresinin kısalmasıyla daha kısa sürede iyileşerek, daha 
çabuk taburcu olduklarını gözlemlemişler ayrıca Jlala ve arkadaşları da farklı bir çalışmada benzer şekilde sonuçlar elde etmişler hastaların iyi bilgilendirilmesinin anksiyeteyi de azaltığını belirtmişlerdir ${ }^{[18-20]}$.

Sonuç olarak; çalışmamızda torakotomi ameliyatı öncesi verilen ağrı yönetimi eğitiminin, hastalarda ameliyat sonrası ilk 24 saatteki hem ağrı düzeyini hem de analjeziklerin tüketimini azalttığı saptadık. Gelecekte hastaya preoperatif ağrı eğitiminin bizimde saptadığımız gibi; multidisipliner bir ekip tarafından hastane ortamında yapılması yanında, multimedyada digital platformlarda ve akıllı telefonlarda (smartphones) hastaya ayrıca verilmesininde akut ağrı tedavisinin başarısına ve postoperatif iyileşmeninde hızlanmasına katkı sunacaktır.

Postoperatif ağrının düzgün bir şekilde ölçülüp değerlendirilmesi ve ağrının şiddetine göre tedavi edilmesi; ağrıya bağıı oluşabilecek komplikasyonların örneğin hastanede kalışın uzaması, artmış hemodinamik parametreler, solunum paterninin bozulması, midebarsak peristatizminin bozulması ve en önemlisi ağrının kronikleşmesi açısından çok önemlidir.

\section{KAYNAKLAR}

1. Hancı V, Kiraz HA, Ömür D, Yurtlu BS, Yurtlu DA, ve ark. Postoperative Pain in Children J Anesth Clin Res. 2012,3:6. https://doi.org/10.4172/2155-6148.1000219

2. Kissin I. Preemptive Analgesia Why its effect is not always obvious. Anesthesiology 1996;84:1015-9. https://doi.org/10.1097/00000542-199605000-00001

3. Gerner P. Postthoracotomy pain management problems. Anesthesiol Clin. 2008;26:355-67. https://doi.org/10.1016/j.anclin.2008.01.007

4. Wenk M, Schug SA. Perioperative pain management after thoracotomy. Curr Opin Anaesthesiol. 2011;24(1):8-12. https://doi.org/10.1097/ACO.0b013e3283414175

5. Sağıroğlu G, Kiraz O, Baysal A, Sağıroğlu T, Çopuroğlu E, ve ark. Torakotomi sonrası ağrı tedavisinde meperidin veya morfin ile intravenöz hasta kontrollü analjezi uygulamalarının karşılaştırılması. Turk J Anaesth Reanim 2013;41:1-6.
https://doi.org/10.5152/TJAR.2013.01

6. Büyükyılmaz F, Aştı T. Ameliyat sonrası ağrıda hemşirelik bakımı. Atatürk Üniversitesi Hemşirelik Yüksekokulu Dergisi, 2009;12:2.

7. Anıl A, Kaya F, Yavaşcaoğlu B, Mercanoğlu E, Türker E ve ark. Comparison of postoperative analgesic efficacy of intraoperative single-dose intravenous administration of dexketoprofen trometamol and diclofenac sodium in laparoscopic cholecystectomy. Journal of Clinical Anesthesia 2016;32:127-33. https://doi.org/10.1016/j.jclinane.2016.02.020

8. Yüceer S. Torakotomi Sonrası Uygulanan Transkütan Elektriksel Sinir Stimülasyonunun Ağrı Üzerine Etkisi (Doktora Tezi). Hacettepe Üniversitesi Sağlık Bilimleri Enstitüsü.

9. Erden S, Şenol Çelik S. Torakotomi sonrası ağrı ve analjezi yöntemlerinin kullanılmasında hemşirenin rolü. Ankara Sağlık Bilimleri Dergisi 2013;2(1-2-3):11-24. https://doi.org/10.1501/Asbd_0000000039

10. Sagiroglu G, Baysal A, Kiraz O, Meydan B, Taşçı A, et al. Comparison of continuous use of thoracic epidural analgesia and intercostal block for pain management after thoracotomy. Anaesthesıology And Intensive Care 2013;10(3):244-50. https://doi.org/10.5114/kitp.2013.38100

11. Çilingir D, Candaş B. Cerrahi sonrası hızlandırılmış iyileşme protokolü ve hemşirenin rolü. Anadolu Hemşirelik ve Sağlık Bilimleri Dergisi, 2017;20:2

12. Erdine S. Ağrı mekanizmaları ve ağrıya genel yaklaşım Ağrı (Erdine S) 3.Baskı. İstanbul Nobel Kitapevi 2007;3748.

13. Tiippana E, Nelskylä K, Nilsson E, Sihvo E, Kataja M, Kalso E. Managing post-thoracotomy pain: Epidural or systemic analgesia and extended care - A randomized study with an "As Usual" control group. Scandinavian Journal of Pain 2014;5(4):240-7.

https://doi.org/10.1016/j.sjpain.2014.07.001

14. Kol E, Alpar Ecevit Ş, Erdoğan A. Preoperative Education and Use of Analgesic Before Onset of Pain Routinely for Postthoracotomy Pain Control Can Reduce Pain Effect and Total Amount of Analgesics Administered Postoperatively. Pain Manag Nurs, 2014;15(1):331-9. https://doi.org/10.1016/j.pmn.2012.11.001

15. Sakakura N, Usami N, Taniguchi T, Kawaguchi K, Okagawa T, Yokoyama et al. Assessment of Long-Term Postoperative Pain in Open Thoracotomy Patients: Pain Reduction by The Edge Closure Technique. Annals of Thoracic Surgery 2010;89(4):1064-70. https://doi.org/10.1016/j.athoracsur.2010.01.015 
16. Mesbah A, Yeung J, Gao F. Pain after thoracotomy, BJA Education 2016;16(1):1-7.

https://doi.org/10.1093/bjaceaccp/mkv005

17. Slinger P, Kanellakos G. Post-operative Analgesia for Thoracic Surgery. US Surgery. Reference Section, 2007;1-5. Hill, p. 569-619.

18. Shelley B, Macfölgeie A, Kinsella J. Anesthesia for thoracic surgery: A survey of UK practice. J Cardiothorac Vasc Anesth. 2011;25:1014-7. https://doi.org/10.1053/j.jvca.2011.06.018
19. Gürlek Ö, Yavuz M. Cerrahi Kliniklerde Çalışan Hemşirelerin Ameliyat Öncesi Hasta Eğitimi Uygulama Durumları. Anadolu Hemşirelik ve Sağlık Bilimleri Dergisi 2013;16(1):8-15.

20. Lanza FL, Chan FK, Quigley EM; Practice Parameters Committee of the American College of Gastroenterology. Guidelines for prevention of NSAID-related ulcer complications. Am J Gastroenterol 2009;104:728-38. https://doi.org/10.1038/ajg.2009.115 